\title{
Diabetes Education in Family: Risk Factors and Barriers to Diabetes Care in Mexican Children and Adolescents
}

\author{
María del Carmen Enríquez Leal ${ }^{1}$, María del Socorro Saucedo Tamayo ${ }^{1}$, María Guadalupe \\ Vidal Ochoa ${ }^{2}$, Martha Nydia Ballesteros Vásquez', Rosa María Cabrera Pacheco', \\ Cecilia Adriana Montaño Figueroa ${ }^{1}$ and María Isabel Ortega Vélez ${ }^{1 *}$
}

\author{
${ }^{1}$ Nutrition Division, Centro de Investigación en Alimentación y Desarrollo, A.C. Sonora, Carretera a la Victoria \\ Km.0.6 Col. La Victoria, Hermosillo, Sonora 83304, Mexico \\ ${ }^{2}$ Department of Endocrinology, Instituto Mexicano del Seguro Social, No Reeleccion 311, Col. Centro. Cd. \\ Obregón, Sonora 85000, México
}

\begin{abstract}
Objective: To determine barriers related to metabolic control and diabetes care in Mexican children and their families.

Design: This was a cross-sectional study designed in two stages. First stage was an assessment of risk factors for inadequate metabolic control ( $\mathrm{HbA} 1 \mathrm{c}$ higher than ADA guidelines by age group) of diabetic children using a logistic regression model. The data sources were 91 clinical files provided by public health institutions at northwest Mexico. Second stage included the design, implementation and evaluation of an educational program (EP) based on the Medical Nutrition Therapy (MNT) and the Social Cognitive Theory (SCT), accounting for critical risk factors identified previously. Twenty five children ( 2 to 14 years old) with type 1 diabetes and their parents agreed to participate in the EP, which promoted healthy behavioral changes regarding diet, physical activity and medical treatment over a 4-month period.
\end{abstract}

Results: Metabolic control was related to the joint effects of families low socioeconomic level and mother's low education attainment $(\mathrm{OR}=8.5, \mathrm{Cl} 95 \%: 1.73,42.16)$, as well as following a conventional treatment $(\mathrm{OR}=5.0, \mathrm{Cl} 95 \%: 1.09,22.82)$. After program implementation participants' mean glycated hemoglobin (HbA1c) decreased $(9.1 \% \pm 1.8 \%$ to $8.3 \% \pm 2 \%$; $\mathrm{P}=0.06$ ). Qualitative content analysis of post-intervention interviews showed that low income, clinical inertia, and lack of social support were barriers to metabolic control of diabetes.

Conclusion and Implications: Socioeconomic, educational, and healthcare factors are related to metabolic control in Mexican children with diabetes, although educational programs based on SCT can help increase self-efficacy in patients through modeling and reinforcing activities.

Keywords: Diabetes, Children, Metabolic control, Nutrition, Mexico.

\section{INTRODUCTION}

Diabetes cases are increasing alarmingly among children and adolescents [1]. As a chronic disease, treatment goals for diabetes include achieving an optimal lipid profile, blood pressure, and glycemic control. Consequently, primary care providers may play a key role in the patient's disease management [2]. However, in developing countries the management of chronic diseases is based on paternalistic models of healthcare where patients are passive actors [3]. In fact, the standard medical care in Mexico provides limited time for patient education, and does not emphasize social, cultural, and emotional aspects related to the patient's self-efficacy to treat their disease [4]. As such, diabetes education based on theoretical education models and health promotion is still a challenge; effectiveness of traditional methods has been questioned [4, 5]. In addition, diabetes

*Address correspondence to this author at the Nutrition Division, Centro de Investigación en Alimentación y Desarrollo, A.C., Carretera a La Victoria Km. 0.6. Hermosillo, Sonora 83304, México; Tel: +52 6622892400 ext., 295; Fax: +52 662280 0094; E-mail: iortega@ciad.mx education cannot be delivered over the limited time that the health providers spend with each patient [6].

Our previous study in Mexican children and adolescents with diabetes, showed an incidence rate of 3.6 cases per 100,000 persons, and an inadequate metabolic control, according to $\mathrm{HbA} 1 \mathrm{c}$ values by age group established by the American Diabetes Association (ADA) [7] (MC; 61\%), which was related to the socioeconomic environment [8]. Biological, emotional, and socio-cultural factors involved in metabolic control can be different among diverse social groups [6-8]. Therefore, nutritional education to improve patients' understanding and addressing these factors in an intervention in a target population is a major task [9]. Although familial and socioeconomic conditions are difficult to change, some context-related strategies can be developed.

Education is the cornerstone of diabetes care $[9,10]$ and self-management education is the key to achieving successful outcomes. Although knowledge and information are necessary for patients, it is not enough to perform behavioral changes. Leaders in diabetes 
education emphasize the importance of using health behavior change theories and models to drive selfmanagement efforts [1]. One of the most utilized theories in diabetes educations is Social Cognitive Theory (SCT) [4].

According to Bandura's SCT, self efficacy is the center of self-management practices, both by itself, and by its effect on outcome expectations and on sociostructural factors. According to SCT, behaviors result from dynamic interactions not only between personal characteristics, but also with the environment. The SCT suggests that human behaviors can be learned through observation [11]. Because dietary behaviors develop in a family context beginning in early childhood, parents can influence their children's social and physical environment. Also, considering that intensive type 1 diabetes therapy (three or more insulin injections and frequent glucose monitoring) has proven to effectively reduce diabetes complications, compared with conventional therapy (one or two daily insulin injections) [12], families can play a meaningful role in managing diabetes, since young children are unable to manage diabetes on their own; for that reason, selfcare education must be provided to the whole family and there should be a gradual transition toward independent management [7].

The purpose of the current study was to identify main risk factors related to MC that are important mediators in planning a nutritional intervention based on SCT, and evaluate its impact on MC as well as identify key barriers and facilitators to adequate $M C$ in Mexican children with type 1 diabetes.

\section{METHODS}

\section{Study Participants}

Participants were recruited by intentional nonprobabilistic sampling from health institutions in Sonora, Mexico. In a previous study [8], we identified a total of 122 children and adolescents diagnosed with type 1 diabetes during the period of 2000 to 2006; we invited to join an educational program (EP) for diabetes management to 53 of those patients, considering that their clinical files were the most complete and that they were living in the Capital City (Hermosillo). Twenty-five families agreed to participate in the program. Figure 1 shows the recruitment strategy used to identify eligible families. Ethical aspects were considered during the selection process in accordance with the Research Center for Food and Development (CIAD, A.C.), Ethics
Committee and home visits were conducted to obtain informed consent.

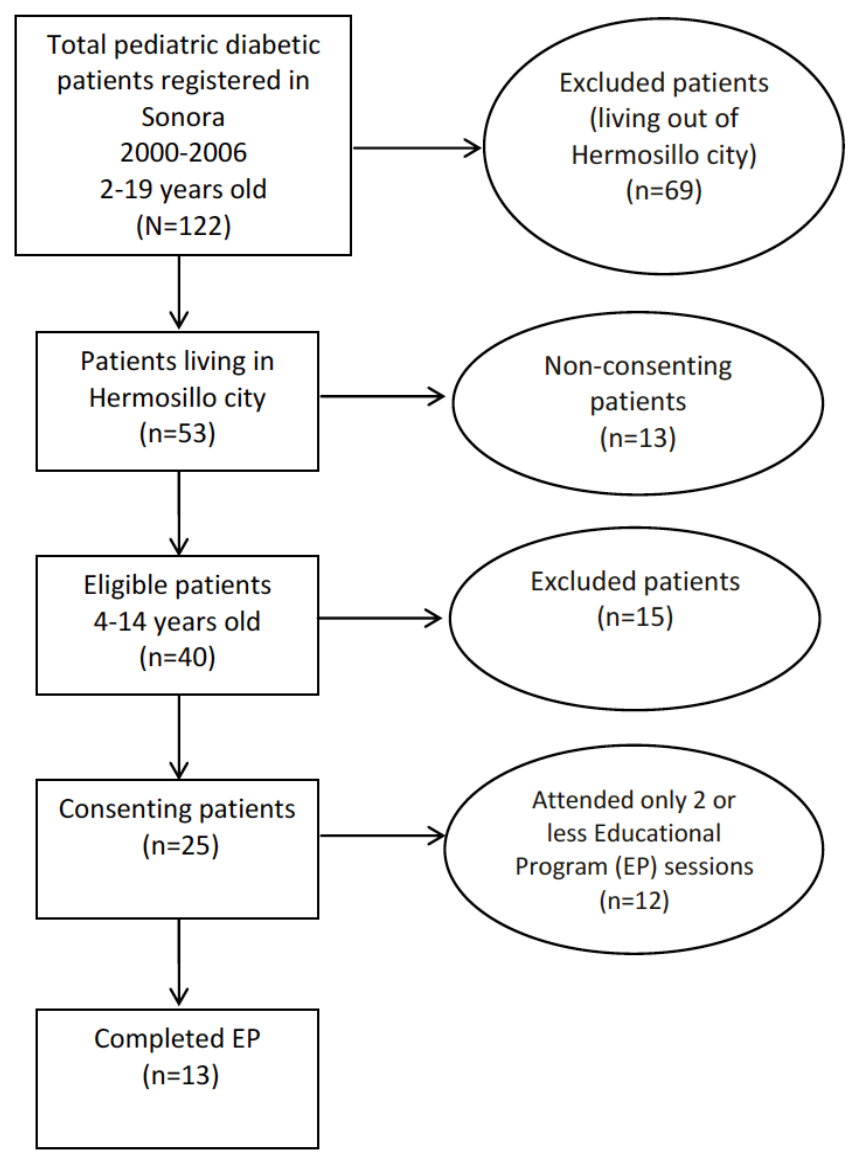

Figure 1: Recruitment of participants in each study stage.

\section{Study Design and Methods}

The study consisted of two stages: a) an evaluation of risk factors for impaired MC in Mexican children and adolescents, and b) a quasi-experimental design, delivery and evaluation of an EP for diabetic pediatric patients and their families.

Characteristics such as age, gender, socioeconomic level (SEL; measured as the parent's annual income and rated as low, $\leq$ US $\$ 5,184$; medium, US $\$ 5,184-8,640$; and high, $\geq$ US $\$ 8,640$ ), parent's marital status (married, single, or divorced), parent's education level (years of study), parent's occupation, type of medical treatment such as conventional (one or two insulin injections/day) or intensive (3 or more injections of insulin/day, and frequent monitoring of blood glucose levels), healthcare services (public or private), physician's specialty (pediatrician, internist, and pediatric endocrinologist) were obtained and analyzed to identify risk factors related to $M C$ in order to consider modifiable factors for planning the EP. 
Body weight and height were measured using a FV 150-KA1 electronic scale (A\&D Company, Ltd. Tokyo, Japan) and a Holtain Stadiometer (Holtain Ltd. Dyfed, U.K.). Body Mass Index (BMI; $\mathrm{kg} / \mathrm{m}^{2}$ ) was calculated from these two measurements. The National Center for Health Statistics/World Health Organization International Growth References was used to determine the participant's nutritional status [13, 14]. Body fat (\% BF) was measured by bioelectrical impedance analysis (BIA) using a BIA-101A analyzer (RJL Systems. Michigan, USA. 1981). Systolic and diastolic blood pressure was measured using a Littmann Classic II S.E. Stethoscope (3M. Minnesota, USA) and a Mercurial Sphygmomanometer Desk MD3600 (Home Care).

Fasting (12 h) blood samples for each subject were collected into tubes containing $0.15 \mathrm{~g} / 100 \mathrm{~g}$ EDTA to determine plasma lipids. Total cholesterol was determined by enzymatic methods using Roche Diagnostic's standards and kits [15]. Triglycerides were determined using Roche-Diagnostic kits, which adjust for free glycerol [16]. HDL cholesterol (HDL-C) was measured in the supernatant left after precipitation of apo B-containing lipoproteins [17]. LDL cholesterol (LDL-C) was determined using Friedewald's equation [18]. Glycated hemoglobin (HbA1c) was determined using the Tina-quant ${ }^{\circledR}$ Hemoglobin $\mathrm{A} 1 \mathrm{Cll}$ technique [19, 20] in a ROCHE/Hitachi 911 Automatic Analyzer (Roche Diagnostics. Massachusetts, USA. 1997).

Dietary intake was evaluated using two 24-hour dietary recalls using the multiple pass method [21] before and after the intervention. Food models and pictures were used, as well as home measures of containers. Analysis of dietary components followed the procedure described by Ortega et al. [22] using a food dictionary with food items from the USDA food data bank [23], and food composition data for the Mexican population [24]. Physical activity was assessed only at baseline using two methods; a Physical Activity Questionnaire [25] and a Bodytronics Pro Cal Calorie Pedometer (TKO Enterprises Inc. Fayetteville, GA. 2005).

\section{Educational Program Design and Delivery}

Risk factors regarding $M C$ obtained in the first stage were used to design the EP. The program was delivered to three groups during 4 months: parents, children aged 4-10 yr, and adolescents aged 11-14 yr. Groups met 14 times during the intervention period, with sessions lasting 3 to 4 hours per session. An interactive educational intervention included motivational and weekly instructional sessions related to diabetes. Every session consisted of interactive and motivational talks with parents and children, as well as reinforcing workshops with parents and adolescents. Small children (4 to 10 years) participated in playful activities regarding healthy feeding and physical activity. An overview of intervention content can be seen in Table 1. Three specialists (diabetes educator, pediatric endocrinologist, and clinical psychologist) delivered the program to parents (as young children caretakers) and adolescents. Main emphasis of EP was to enable children with diabetes and their parents to become self-sufficient in caring for their disease based on SCT observational learning, self-efficacy, and reinforcing constructs.

Table 1: Educational Program (EP) Themes and Activities

\begin{tabular}{|c|c|}
\hline \multicolumn{2}{|c|}{ Intervention } \\
\hline Topics of the 14 Weekly Sessions & Sessions Format \\
\hline $\begin{array}{ll}\text { - } & \text { Motivational introduction: "The family" } \\
\text { - } & \text { Diabetes overview } \\
\circ \quad \text { Giabetes and nutrition } \\
\circ \quad \text { Nutritional pyramid } \\
\circ \quad \text { Nutritional groups } \\
\circ \quad \text { Carbohydrate counting } \\
\circ \quad \text { Reading nutritional labels } \\
\circ \quad \text { Glycemic index } \\
\circ \quad \text { Medical treatment } \\
\circ \quad \text { Physical activity } \\
\circ \quad \text { Coping with stress (two sessions) } \\
\circ \quad \text { Diabetes complications }\end{array}$ & $\begin{array}{l}\text { - Motivational discussions (role playing, popular persons with } \\
\text { diabetes, peer support) } \\
\text { - } \quad \text { Treatment application and healthy dietary choices } \\
\text { - } \quad \text { Demonstrations } \\
\text { - } \quad \text { Achievement discussions } \\
\text { - } \quad \text { Coping with environmental barriers discussion }\end{array}$ \\
\hline
\end{tabular}




\section{Program Evaluation}

Anthropometric, dietary, and clinical indicators were obtained at the end of the intervention program. In addition, facilitators and impediments were analyzed in a structured interview with parents (typically mothers) nine months later, focusing on nutrition, physical activity and medical treatment. Interviews were audio recorded and successively transcribed verbatim by members of the research team. Grounded in a deductive process [26], a preliminary codebook was developed based on the interview guides and the primary aims of this study. In addition to the deductive codes, a thematic analysis of the data led to the supplementation of the codebook with themes that emerged throughout assessment of the transcripts.

\section{Data Analysis}

All outcome data were examined using descriptive statistics and paired t-test. Factor analysis (Chronbach's alpha) was used to determine questionnaire reliability. A logistic regression model was used to determine Odds Ratios and 95\% confidence intervals between MC (adequate or inadequate) and sociodemographic and clinical variables. Statistical analyses were done using the statistical software, SPSS version 14.0 (SPSS Inc. Chicago IL. 2005). Qualitative data analyses were coded and analyzed using NVivo 7 qualitative software (QSR International Pty. Ltd. Australia. 2007).

\section{RESULTS}

\section{Risk Factors for Metabolic Control}

The logistic regression model showed no relationship between MC (HbA1c values) and sociodemographic and clinical variables (individual variables). However, families with low SEL and use of conventional treatment, low SEL and pediatric care (OR, 3.1, 95\% Cl, 1.1, 9.2), and low SEL and low education (OR, $8.5,95 \% \mathrm{Cl}, 1.7,42.2)$ were more likely to have an inadequate $\mathrm{MC}$ (Table 2).

Twenty five families attended the educational intervention, and patients were $10.7 \pm 3.2$ years old (17 females, 8 males). Half the families had low SEL (family annual income of US $\$ 0-5184$ ) and mother's and father's average years of formal education was $10.3 \pm 3.1$ and $9.8 \pm 4.5$, respectively.

Only $12 \%$ of patients received medical care from a pediatrician, and $65 \%$ by a general health practitioner. Twelve families did not complete all EP sessions (Figure 1), but attended at least two sessions regarding diabetes overview and medical treatment. Main reasons for leaving the program were parent's lack of time, health complications, and moving out of town. Furthermore, families who left the EP belonged to single-parent homes (67\%), had lower parent education (9.5 \pm 3.3 years) and SEL (22\% low-income and $78 \%$ middle-income).

Table 3 shows patients' clinical and MC characteristics. Thirty-six percent of patients showed pre-hypertension, $16 \%$ were overweight, and $12 \%$ were obese. In addition, according to the cut off percentiles from the National Cholesterol Education Program (NCEP) [27], participants had HDL-C values within the $25^{\text {th }}$ percentile and triglycerides within the $75^{\text {th }}$ percentile. In contrast, total cholesterol and LDL-C levels were below the 50th percentile for the age range of patients. Furthermore, $72 \%$ of patients had $\mathrm{HbA} 1_{\mathrm{c}}$ levels above those recommended according to age [7].

After the EP, $60 \%$ of patients used an intensive medical treatment compared with $26 \%$ at baseline. No

Table 2: Relationship of Metabolic Control (MC), Sociodemographic and Clinical Variables

\begin{tabular}{|c|c|c|c|}
\hline Indicator ${ }^{*}$ & Odds Ratio & $\begin{array}{c}95 \% \mathrm{Cl} \\
\text { of Odds Ratio }\end{array}$ & $P$ Value \\
\hline Treatment type & 0.9 & $0.4-1.9$ & 0.734 \\
\hline Physician specialty (PS) & 2.5 & $0.5-13.9$ & 2.529 \\
\hline Healthcare services & 0.9 & $0.4-2.3$ & 0.905 \\
\hline Mother's education & 1.1 & $0.8-1.6$ & 0.365 \\
\hline Low SEL ${ }^{* *} x$ conventional treatment & 5.0 & $1.1-22.8$ & 0.038 \\
\hline Low SEL $x$ pediatric care & 3.1 & $1.1-9.2$ & 0.037 \\
\hline Low SEL $x$ low mother's education & 8.5 & $1.7-42.2$ & 0.008 \\
\hline
\end{tabular}

Variables included in the analysis: age, parent's education, parent's legal status, parent's occupation, BMI, type of treatment, healthcare services, physician specialty, and number of hospitalizations; "n=122; " $\mathrm{SEL}=$ Socioeconomic level; $\mathrm{Cl}=$ confidence interval. 
Table 3: Clinical and Metabolic Control Values of Diabetic Patients at Baseline and Post-Intervention

\begin{tabular}{|c|c|c|c|}
\hline \multirow[b]{2}{*}{ Indicator } & \multirow{2}{*}{$\begin{array}{l}\text { Baseline* }^{*} \\
(X \pm S D)\end{array}$} & \multicolumn{2}{|c|}{ Intervention $^{* *}$} \\
\hline & & $\begin{array}{l}\text { Pre-Intervention } \\
\qquad(X \pm S D)\end{array}$ & $\begin{array}{l}\text { Post-Intervention } \\
\qquad(X \pm S D)\end{array}$ \\
\hline $\mathrm{BMI}\left(\mathrm{kg} / \mathrm{m}^{2}\right)$ & $19.2 \pm 3.6$ & $18.4 \pm 2.7$ & $18.6 \pm 2.7$ \\
\hline Body fat (\%) & $23.8 \pm 7.7$ & $22.7 \pm 7.5^{\mathrm{a}}$ & $19.9 \pm 7.4^{b}$ \\
\hline Diastolic blood pressure $(\mathrm{mm} \mathrm{Hg})$ & $73 \pm 9$ & $73 \pm 9.5$ & $71 \pm 7$ \\
\hline Total cholesterol (mg/dL) & $132.7 \pm 20.8$ & $128.8 \pm 21.2$ & $142.4 \pm 17$ \\
\hline LDL C (mg/dL) & $63.4 \pm 20.5$ & $67.1 \pm 18$ & $68 \pm 20$ \\
\hline $\mathrm{HDL} \mathrm{C}(\mathrm{mg} / \mathrm{dL})$ & $43.1 \pm 9.2$ & $42.9 \pm 10$ & $48.5 \pm 8$ \\
\hline
\end{tabular}

LDL=low density lipoproteins; $\mathrm{HDL}=$ high density lipoproteins; $\mathrm{HbA} 1 \mathrm{c}=$ glycated hemoglobin.

"Total intervention participants $(n=25)$.

${ }_{* * *}^{* *}$ Considering only patients who completed the EP $(n=13)$.

$p=0.06$.
${ }_{a, b}$ Different superscripts in the same row indicate significant differences $(p<0.05)$.

changes were observed in $\mathrm{BMI}$; however, body fat decreased at post-intervention (from $22.7 \%$ to $19.9 \%$, $p=0.009$ ). There were no significant differences in blood pressure, LDL-C, total cholesterol, or HDL-C at post-intervention. However, as HDL-C was below recommendations at the beginning, we observed an increasing trend at post-intervention. A significant increase in triglycerides (from the 75th percentile to the 95th percentile) was found after the EP. HbA1 c decreased from $9.1 \%$ to $8.3 \%$ at post-intervention $(p=0.06)($ Table 3$)$.

At baseline, patients had high energy intakes from total and saturated fat. Total energy, dietary fiber, and mono- and polyunsaturated fat consumption were below the recommended levels (Table 4). Total fat and caloric intake increased significantly post-intervention (from $34 \%$ to $38.5 \%$ and from $1556 \mathrm{kcal}$ to $1887 \mathrm{kcal}$, respectively $p<0.05$ ); however, some patients had an energy consumption level below the ADA recommendations [7]. At post-intervention, saturated fat, dietary cholesterol, and mono- and polyunsaturated fat increased significantly $(p<0.05)$. Dietary fiber intake did not increase post-intervention.

Patients were classified as sedentary because they showed $4542 \pm 2136$ steps/day. However, according to the Physical Activity Questionnaire results, 38\% of

Table 4: Mean Daily Dietary Energy, Macronutrient, Cholesterol, and Fiber Intake of Diabetic Patients before and after the Educational Program (EP) $(n=13)$

\begin{tabular}{|c|c|c|}
\hline Nutrient & $\begin{array}{l}\text { Initial } \\
(X \pm S D)\end{array}$ & $\begin{array}{l}\text { Post-Intervention } \\
\quad(X \pm S D)\end{array}$ \\
\hline Energy (kcal) & $1556 \pm 432^{a}$ & $1887 \pm 311^{\mathrm{b}}$ \\
\hline Carbohydrates energy (\%) & $49.9 \pm 9.9$ & $47.6 \pm 5.2$ \\
\hline Protein energy (\%) & $17.7 \pm 3.8$ & $15.6 \pm 2.7$ \\
\hline Total fat energy (\%) & $34 \pm 6.9^{a}$ & $38.5 \pm 4.4^{\mathrm{b}}$ \\
\hline Monosaturated fat energy (\%) & $9.2 \pm 3.7^{\mathrm{a}}$ & $11.9 \pm 2.4^{b}$ \\
\hline Polyunsaturated fat energy (\%) & $6.1 \pm 2.7^{a}$ & $8.4 \pm 3.5^{b}$ \\
\hline Saturated fat energy (\%) & $10.2 \pm 4.7^{\mathrm{a}}$ & $12.4 \pm 4.4^{\mathrm{b}}$ \\
\hline Cholesterol $(\mathrm{mg} / \mathrm{d})$ & $249.3 \pm 116.5^{a}$ & $323 \pm 101^{b}$ \\
\hline Dietary fiber (g/d) & $18.6 \pm 8.3$ & $23.9 \pm 10.1$ \\
\hline
\end{tabular}

${ }^{a, b}$ Different superscripts in the same row indicate significant differences $(p<0.05)$. 
patients had moderate-intensive physical activity (swimming, for example, cannot be measured by pedometer); moreover, $31 \%$ were not engaged in regular physical activity.

\section{Mediating Variables Involved in Diabetes Management}

Information about dietary issues from health services was lacking before the EP, being the most important barrier to a better diabetes care. There was a concern among some parents about caloric intake, being below what was required for their children's age. On the other hand, one third $(31 \%)$ of families had a positive attitude toward improving dietary behaviors and food choices (e.g. including low-fat milk). However, two thirds of participant families $(69 \%)$ had no intention to make positive changes in their dietary intake. In fact, they had negative perceptions toward eating less fat.

I don't know anything about counting carbohydrates; the doctors... did not tell us anything about portions or anything else.

My daughter had a low carbohydrate diet and she kept very good blood levels... but she was dropping too much weight; it's difficult to read the nutritional facts, though I really learned it on the educational program.

Other barriers perceived by patients were a general difficulty to implement the acquired knowledge from the EP frequently due to the low family SEL, lack of social support (family and peers), and an adolescent's aversion to consume "light" products.

Sometimes I can give her (daughter) a good diet... but sometimes I don't have the money to do it.

Regarding regular physical activity, main barriers were the use of technology, lack of compliance, lack of parent's time, and low income.

I believe that most children and youth have become sedentary because of the technology; I usually tell her (daughter) she needs to go walking at afternoon.... and she says, no, no, no I have a stomachache! She comes up with many excuses!; I don't have time because of my job, for several situations we have not been able to do it ... (referring to enrolling her daughter in a physical activity program); I asked her if she would like to do yoga and she said yes, but I do not have the economic resources to enroll her.

Before the EP, most patients were using the conventional medical treatment (monitoring and using insulin once a day). After the program $47 \%$ of patients reported using an intensive treatment, which was recommended during the intervention. Clinical inertia was identified, that is defined as the recognition of a problem but a failure to act on it [28]. Healthcare providers exhibited various levels of clinical inertia, because they did not promote or intensify therapy appropriately. After the EP, parents continued to experience treatment barriers, like the cost of medication (insulin) and test strips for glucose monitoring, lack of family support, and clinical inertia.

Since my daughter was diagnosed, she has been using the same treatment... at morning and afternoon;

My son is still using the conventional system, two injections, one at morning and one at afternoon;

I feel that the intensive treatment requires more monitoring ... which increases the cost significantly.

My oldest daughter helps me with her sister diabetes care, but ... she regrets that I never taught her how to do it...

However, families also identified some facilitators for diabetes care such as family support, self-efficacy, and medical prescriptions.

That was a great help for me (refers to intervention) since my husband started to inject our daughter; I do not have the courage to change the treatment (type of insulin), and when we went there (educational program), we learnt about the different types of insulin ... and we asked her doctor for a rapid insulin prescription.

\section{DISCUSSION}

Inadequate $\mathrm{MC}$ is related to low $\mathrm{SEL}$, low education level of mother, healthcare services and physician's specialty (e.g. pediatrician) in Mexican children and 
adolescents. Other studies have reported similar findings between low income, mother's low education level, single-parent families and inadequate MC [2931). Our qualitative data and some characteristics of participants who did not complete the program, confirmed that low SEL in these families explained the inadequate glucose monitoring and children's physical activity. These results indicate that a diabetes program for low SEL families that focuses only on self-efficacy will have low or none impact on patients MC. Bandura's approach of SCT on health promotion programs stresses the importance of social determinants on successful program outcomes [32].

Our patients increased the use of intensive treatment at post-intervention. Knowledge about adjusting insulin doses and nutritional skills were the principal facilitators cited by parents. The Diabetes Control and Complications Trial (DCCT) showed that intensive treatment may reduce disease complications [12]. But, in this study professional health care frequently prescribed the conventional treatment, and this may be the reason to an inadequate MC. Therefore, we speculated the presence of clinical inertia due to the lack of promotion or intensification therapy appropriately. Consequently, strategies to overcome clinical inertia must focus on continued medical education that emphasizes evidence-based guidelines for diabetes care [28].

One of the main barriers to adequate diabetes care cited by parents was the cost of blood glucose monitoring (BGM), similar to other studies [33]. Nevertheless, BGM is used to calculate the insulin dose required to adequate $M C$ [7], and more frequent monitoring is associated with lower HbA1c levels [31, 34]. For that reason, economical strategies for underprivileged patients should be taken into account to improve the financial burden of diabetes among youths [35]; although BGM is costly, its long term benefits outweigh the expenses.

Institutional attitudes toward the incorporation of dietary management, appropriate treatments, and physical activity lifestyles have a positive impact in children with diabetes [35]. Evidence has suggested that patients need to actively participate on daily decisions involved in diabetes management [10].

Diabetes educators can become a cornerstone in the management of the disease among young patients and their parents [6]. Diabetes educators should be integrated into the diabetes interdisciplinary team in the
Mexican healthcare services. In addition, the quantification of risk factors that can be modified, such as type of medical treatment, must be taken into consideration when planning diabetes education to maximize program effectiveness.

We observed some positive changes after the intervention. HbA1c level decreased $(\sim 1 \%)$, which suggests a better glucose control due to a major efficacy in management of medical treatment. Also, we observed a positive clinical change in HDL-C concentrations; however it was below recommendations. On the contrary, there was an increase in serum triglycerides content. These findings indicate the presence of risk factors for cardiovascular disease among study children. Same results have been reported previously for adults and children in the study region [36]. Nevertheless, the TC/HDL-C ratio remained without change, both before and after the intervention. This has been recognized as a low ischemic heart disease risk [37].

Considering that a third of participants showed impaired physical growth (data not shown) and a low caloric intake at baseline, an adequate caloric intake was advised. This could be the reason why at postintervention we found a significant increase in caloric and especially total and saturated fat intake. Other studies have also reported an average high saturated fat intake, ranged from $11 \%$ to $15 \%$ [38]. This situation revealed a dietary pattern with high consumption of animal foods, that is common among the population of northwestern Mexico [36, 39].

When there is a restriction on total caloric intake, high fat, low carbohydrates diets have been related to high triglycerides concentrations [40]. However, a potential confounding factor is free glycerol concentrations, as these are measured in the triglycerides assay and are high in persons with diabetes [41]. Free glycerol concentrations could be present in participants of this study due to adipocytes removal during body fat loss, especially considering the short period of intervention.

On the other hand, the US Center for Disease Control and Prevention (CDC) recommends that youths participate in 30 minutes of moderate-to-vigorous physical activity daily [42]. In this group, only one third of patients fulfilled the CDC recommendations. Lack of parent's time, compliance, and economic resources were cited as reasons for not exercising. Other barriers to physical activity among adults with type 2 diabetes in 
the same region were weather (up to $138{ }^{\circ} \mathrm{F}$ during summer), and neighborhood insecurity [33]. We considered that patients increased their level of physical activity during the intervention due to the reduction in percentage of body fat and a tendency toward increasing HDL-C.

Additionally, parents enrolled in this study expressed a high level of satisfaction with the coping with stress sessions and were interactively involved in exchanging knowledge, experiences, and discussing problems with other group members. As Bandura discusses "modifying self-beliefs of efficacy, can reduce people's stress reactions, alter their negative emotional proclivities and correct misinterpretations of their physical states" [32].

The theoretical approach used in our intervention addressed the social as well as the personal determinants of health. However, we recognize the need to change some social practices that have widespread detrimental effects on health rather than solely changing individual habits [32, 43]. In this study we used modeling of self-management skills, modeling transmitted knowledge, perceived self-efficacy, perceived facilitators and impediments constructs to achieve behavior change. In addition, parents discussed on how they could take control of some environmental factors (type of treatment); however some barriers reside within the health and social system rather than in personal or situational impediment [43].

The strengths of the current study include elements that are not considered in our actual healthcare services: the evaluation of risk factors related to MC in the target population, a multidisciplinary team, intensity of the intervention, interactive teaching methods, family involvement, and theory-based program design. A limitation was the low participation rate, which might lead to insufficient statistical power to detect changes. Also, those participants that completed the EP had a lower $\mathrm{HbA} 1 \mathrm{c}$ and higher SEL than those who attended partially; therefore, generalizations should be taken with caution. On the other hand, our qualitative inquiry provided us evidence supporting our quantitative results, and allowed us to better understand social contexts of participant families.

In conclusion, socioeconomic, educational, and healthcare factors are related with $M C$ in Mexican children with diabetes. A better understanding of factors that contribute to clinical inertia could be beneficial to care providers in developing countries. Diabetes educators within the Mexican Health System is a priority, but it should be a joined effort with a public policy aimed to support low SEL families regarding healthy feeding and cost of medical treatment. In addition, long-term studies are needed to determine whether benefits of educational programs are maintained over time. Finally, interventions based on SCT can help increase self-efficacy in patients with diabetes through modeling, reinforcing and coping constructs.

\section{IMPLICATIONS FOR RESEARCH AND PRACTICE}

Using theory-based diabetes education could be a useful tool for professional health care practitioners to develop self-efficacy among pediatric diabetes patients. Nutrition education programs can change food choices and dietary practices through changes in perceptions, attitudes, beliefs, meanings, social norms, and selfefficacy. However, as Bandura proposes, it will be necessary a change on social systems that have detrimental effects on health, to assure truly effective changes on present and future health of diabetic children.

\section{REFERENCES}

[1] Knip M. Etiopathogenetic aspects of type 1 diabetes. In Chiarelli F, Dahl-Jørgensen K, Kiess W, editors. Diabetes in Childhood and Adolescence. Basel, Switzerland: Karger 2005; pp. 1-27. http://dx.doi.org/10.1159/000085775

[2] Armour TA, Norris SL, Jack L, Zhang X, Fisher L. The effectiveness of family interventions in people with diabetes mellitus: a systematic review. Diabet Med 2005; 22: 1295305.

http://dx.doi.org/10.1111/j.1464-5491.2005.01618.x

[3] Barlow J, Wright C, Sheasby J, Turner A, Hainsworth J. Selfmanagement approaches for people with chronic conditions: a review. Patient Educ Couns 2002; 48: 177-87. http://dx.doi.org/10.1016/S0738-3991(02)00032-0

[4] Pérez Pastén E. Guía para el paciente y el educador en diabetes. Tercera ed. México, D.F.: Editorial independiente 2003.

[5] Green LW, Kreuter MW. Health promotion planning: an educational and environmental approach. 2nd ed: Mayfield 1991.

[6] Pérez-Pastén E, Pérez-Pastén $P$. Diseño del programa educativo. In: Pérez-Pastén $E$, Pérez-Pastén $P$, editors. Educación en diabetes Manual de apoyo.México, D.F.: Grupo Imagen Publicitario 2004; pp. 24-35.

[7] Silverstein J, Klingensmith G, Copeland K, et al. Care of children and adolescents with type 1 diabetes: a statement of the American Diabetes Association. Diabet Care 2005; 28: 186-212. http://care.diabetesjournals.org/content/28/1/186. short

[8] Enríquez-Leal MC, Montaño-Figueroa CA, Saucedo-Tamayo MS, et al. Incidencia, características clínicas y estado nutricional en niños y adolescentes mexicanos con diabetes. Interciencia 2010; 35: 455-60. 
[9] Contento IR. Nutrition education: linking research, theory, and practice. Asia Pac J Clin Nutr 2008; 17(Suppl 1): 176-9.

[10] Mensing C, Boucher J, Cypress M, et al. National standards for diabetes self-management education. Task Force to Review and Revise the National Standards for Diabetes SelfManagement Education Programs. Diabet Care 2000; 23: 682-9.

http://dx.doi.org/10.2337/diacare.23.5.682

[11] Bandura A. Social cognitive theory of self-regulation. Organ Behav Hum Decis Process 1991; 50: 248-87. http://dx.doi.org/10.1016/0749-5978(91)90022-L

[12] Diabetes Control and Complications Trial Research Group. The effect of intensive treatment of diabetes on the development and progression of long-term complications in insulin-dependent diabetes mellitus: The Diabetes Control and Complications Trial Research Group. N Engl J Med 1993; 329: 977-86. http://dx.doi.org/10.1056/NEJM199309303291401

[13] National Heart, Lung, and Blood Institute. Obesity education initiative expert panel on the identification, evaluation and treatment of overweight and obesity in adults. NIH publication No. 98-4083: 1998.

[14] WHO/NUT/NCD, Obesity. Preventing and managing the global epidemic. World Health Organization, Division of noncommunicable disease and programme of nutrition family and reproductive health. Report of a WHO Consultation Obesity. Geneva 1998.

[15] Allain CC, Poon LS, Chan CS, Richmond W, Fu PC. Enzymatic determination of total serum cholesterol. Clin Chem 1974; 20: 470-5.

[16] Carr TP, Andresen CJ, Rudel LL. Enzymatic determination of triglyceride, free cholesterol, and total cholesterol in tissue lipid extracts. Clin Biochem 1993; 26: 39-42.

http://dx.doi.org/10.1016/0009-9120(93)90015-X

[17] Warnick GR, Benderson J, Albers JJ. Dextran sulfate-Mg2+ precipitation procedure for quantitation of high-densitylipoprotein cholesterol. Clin Chem 1982; 28: 1379-88.

[18] Friedewald WT, Levy RI, Fredrickson DS. Estimation of the concentration of low-density lipoprotein cholesterol in plasma, without use of the preparative ultracentrifuge. Clin Chem 1972; 18: 499-502.

[19] Karl J, Burns G, Engel W, et al. Development and standardization of a new immunoturbidimetric $\mathrm{HbA1c}$ assay. Klin Lab 1993; pp. 991-6.

[20] Bakkeren D, Bonvicini P, Buxeda M, et al. Multicenter evaluation of an improved immunoturbidimetric assay for the determination of $\mathrm{HbA} 1 \mathrm{c}$ on clinical chemistry analyzers. Clin Lab 1999; 45: 123-37.

[21] Conway JM, Ingwersen LA, Vinyard BT, Moshfegh AJ. Effectiveness of the US Department of Agriculture 5-step multiple-pass method in assessing food intake in obese and nonobese women. Am J Clin Nutr 2003; 77: 1171-8.

[22] Ortega M, Quizán P, Morales G, Preciado M. Cálculo de ingestión dietaria y coeficientes de adecuación a partir de: registro de 24 horas y frecuencia de consumo de alimentos. Cuadernos de trabajo 1999; (1).

[23] Geghardt S, Matthews R. Nutritive Value of Foods. USDA. Home and Garden Bulletin Washington, DC. 1981; 72: 1-72.

[24] Instituto Nacional de la Nutrición Salvador Zubirán. Subdirección de nutrición experimental y ciencia de los alimentos. Tablas de composición de alimentos. México 1980; 1 -248

[25] López-Alvarenga JC, Reyes-Díaz S, Castillo-Martínez L, Dávalos-lbáñez A, González-Barranco J. Reproducibilidad y sensibilidad de un cuestionario de actividad física en población mexicana. Salud Pública de México 2001; 43: 30612.

http://dx.doi.org/10.1590/S0036-36342001000400007
[26] Patton MQ. Qualitative research and evaluation methods. 3rd ed. Thousand Oaks, CA: Sage 2002.

[27] American Academy of Pediatrics. National cholesterol education program: report of the expert panel on blood cholesterol levels in children and adolescents. Pediatrics 1992; 89: 525-84.

[28] Phillips LS, Branch JWT, Cook CB, et al. Clinical Inertia. Ann Intern Med 2001; 135: 825-34.

http://dx.doi.org/10.7326/0003-4819-135-9-200111060$\underline{00012}$

[29] Thompson SJ, Auslander WF, White NH. Comparison of single-mother and two-parent families on metabolic control of children with diabetes. Diabet Care 2001; 24: 234-8. http://care.diabetesjournals.org/content/24/2/234

[30] Araujo MB, Mazza CS. Assessment of risk factors of poor metabolic control in type 1 diabetic children assisted in a public hospital in Argentina. Pediatr Diabetes 2008; 9: 480-7. http://dx.doi.org/10.1111/j.1399-5448.2008.00388.x

[31] Johns C, Faulkner MS, Quinn L. Characteristics of adolescents with type 1 diabetes who exhibit adverse outcomes. Diabetes Educ 2008; 34: 874-85. http://dx.doi.org/10.1177/0145721708322857

[32] Bandura A. Health promotion from the perspective of social cognitive theory. Psychol Health 1998; 13: 623-49. http://dx.doi.org/10.1080/08870449808407422

[33] Albarran NB, Ballesteros MN, Morales GG, Ortega MI Dietary behavior and type 2 diabetes care. Patient Educ Couns 2006; 61: 191-9. http://dx.doi.org/10.1016/j.pec.2005.03.008

[34] Hood KK, Butler DA, Volkening LK, Anderson BJ, Laffel LM. The blood glucose monitoring communication questionnaire an instrument to measure affect specific to blood glucose monitoring. Diabetes Care 2004; 27: 2610-5. http://dx.doi.org/10.2337/diacare.27.11.2610

[35] Daneman D. State of the world's children with diabetes Pediatr Diabetes 2009; 10: 120-6. http://dx.doi.org/10.1111/j.1399-5448.2008.00479.x

[36] Ballesteros MN, Cabrera RM, Saucedo MS, Aggarwal D, Shachter NS, Fernandez ML. High intake of saturated fat and early occurrence of specific biomarkers may explain the prevalence of chronic disease in northern mexico. J Nutr 2005; 135: 70.

[37] Lemieux I, Lamarche B, Couillard C, et al. Total cholesterol/HDL cholesterol ratio vs LDL cholesterol/HDL cholesterol ratio as indices of ischemic heart disease risk in men: the Quebec Cardiovascular Study. Arch Intern Med 2001; 161: 2685-92. http://dx.doi.org/10.1001/archinte.161.22.2685

[38] Helgeson VS, Viccaro L, Becker D, Escobar O, Siminerio L. Diet of adolescents with and without diabetes: trading candy for potato chips? Diabetes Care 2006; 29: 982-7. http://dx.doi.org/10.2337/dc05-2197

[39] Ortega M, Valencia M. Measuring the intakes of foods and nutrients of marginal populations in north-west Mexico Public Health Nutr 2002; 5: 907-10. http://dx.doi.org/10.1079/PHN2002379

[40] Franz MJ, Bantle JP, Beebe CA, et al. Evidence-based nutrition principles and recommendations for the treatment and prevention of diabetes and related complications. Diabetes Care 2002; 25: 148-98. http://dx.doi.org/10.2337/diacare.25.1.148

[41] Patton SR, Dolan LM, Powers SW. Mealtime interactions relate to dietary adherence and glycemic control in young children with type 1 diabetes. Diabetes Care 2006; 29: 10026 .

http://dx.doi.org/10.2337/dc05-2354 
[42] Lustman PJ, Anderson RJ, Freedland KE, De Groot M, Carney RM, Clouse RE. Depression and poor glycemic control: a meta-analytic review of the literature. Diabetes Care 2000; 23: 934-42.

http://dx.doi.org/10.2337/diacare.23.7.934
[43] Bandura A. Health promotion by social cognitive means. Health Educ Behav 2004: 31: 143-64

http://dx.doi.org/10.1177/1090198104263660

Received on 28-09-2015

http://dx.doi.org/10.6000/1929-4247.2015.04.04.2

(C) 2015 Enríquez et al.; Licensee Lifescience Global.

This is an open access article licensed under the terms of the Creative Commons Attribution Non-Commercial License (http://creativecommons.org/licenses/by-nc/3.0/) which permits unrestricted, non-commercial use, distribution and reproduction in any medium, provided the work is properly cited. 